\title{
Effect of Electrolyte Lignin and Fly Ash in Stabilizing Black Cotton Soil
}

\author{
B. M. Lekha ${ }^{1}$ - Goutham Sarang ${ }^{1}$. \\ A. U. Ravi Shankar ${ }^{1}$
}

Accepted: 9 March 2015 /Published online: 2 April 2015

(C) Springer New York 2015

\begin{abstract}
Subgrade is one of the important layers of any pavement. It must be able to support loads transmitted from pavement structure without excessive deformation under adverse climatic and traffic conditions. In this investigation, laboratory studies were carried out to evaluate the influence of a commercial electrolyte lignin stabilizer (ELS), fly ash (FA) and a combination of both, on black cotton (BC) soil procured from North Karnataka region in India. Basic geotechnical and engineering properties like unconfined compressive strength (UCS), California bearing ratio (CBR), etc. were determined for both untreated and treated soil. Dynamic repeated load test was conducted to examine the fatigue behaviour of the soil. Durability of the soil was checked by wet-dry (WD) and freeze-thaw (FT) cycle tests, and swelling properties by free swell index test. From the studies, it was observed that consistency limits, dry density, UCS and CBR values were improved for treated soil, with curing periods of 1 , 7 and 28 days. Weight loss in FT test was less than $14 \%$ for 12 cycles, which ensures that the stabilized soil has become durable. But none of the samples were observed to be withstanding above five cycles in wet-dry test. Soil stabilized with ELS and FA showed better results compared to soil with only ELS. Swelling was reduced to a great extent with 28 days curing period for the former one. From the experimental results, it can be concluded that this chemical can be used as a stabilizer for existing BC soil in site to enhance its subgrade strength.
\end{abstract}

Keywords Soil stabilization · ELS · Fly ash · UCS · CBR · WD and FT test · Fatigue life

B. M. Lekha

lekhabm@gmail.com

Goutham Sarang

gouthamsarang@gmail.com

A. U. Ravi Shankar

aurshankar@gmail.com

1 Department of Civil Engineering, National Institute of Technology, Karnataka, Surathkal, Srinivasnagar PO, Mangalore, Karnataka 575025, India 


\section{Introduction}

Subgrade is an important pavement layer, which supports loads transmitted from pavement structure without excessive deformation under adverse climatic and traffic conditions. Soil stabilization is required when the available soil for construction is not suitable for the intended purpose. In a broad sense, stabilization is the process involving compaction, pre-consolidation, drainage, etc. in various stages. The process may include the blending of soils to achieve a desired gradation or the mixing of suitable additives which may lead to changes in the original soil gradation, texture or plasticity characteristics, or act as a cementation material of the soil [1]. Soil stabilization is used to reduce the permeability and compressibility of the soil mass in earth structures, to reduce the swelling in case of expansive soils and to increase its shear strength.

\section{Black Cotton Soil}

Black cotton (BC) soil, being expansive in nature, exhibits large volumetric variations caused by moisture fluctuations from seasonal changes and considered as one of the problematic soils by the highway engineers. Problems associated with BC soil, located in many regions in Karnataka, India, particularly in the North Karnataka province, are well known. During the last few decades, damage due to swelling action has been observed clearly in these regions in the form of cracking and breakup of pavements, building foundations, embankments and irrigation systems. One method to control the volume changes of expansive soil is to stabilize it with admixtures that prevent it from volume changes or adequately modify the volume changes characteristics of expansive soil. The removal of expansive soils and replacement with suitable fill material is a commonly adopted solution in these areas. However, feasibility of this method depends on the availability of preferred fill material within a suitable distance, the thickness of the weak subgrade soil to be replaced and ultimately the cost and time involved. Chemical stabilization is another alternative being applied worldwide even if the method is at a judging stage in India.

\section{Literature Review}

Several studies have been conducted on the use of sulfite lignin in various civil engineering applications. Some studies have demonstrated that sulfite lignin is effective in soil stabilization and dust control for unpaved roads [2, 3]. Nicholls and Davidson [2] confirmed that lignin admixtures indeed improve some engineering properties related to soil stability. It was also reported that the strength of lignin-treated soil increases rapidly with an increase in the duration of air curing. Gow et al. [4] used lignosulfonate to treat a soil-aggregate mixture and determined its effectiveness by California bearing ratio (CBR) test. For unsoaked specimens, CBR value showed higher improvement after 1 week curing, whereas for soaked specimens, the improvement was slightly less than that for unsoaked ones. This may be due to the water loving behaviour of lignosulfonate. Adding lignin to clay soils increases soil stability by causing dispersion of the clay fraction [5]. Investigations showed that lignosulfonate along with a small amount of sulphuric acid was helpful in improving the shear strength and resilient modulus of cohesive soil $[6,7]$. Many types of polymers are generally 
considered as good soil stabilizers. Hydrocarbon chains in polymers become entwined within the soil particles to make the soil stabilized. Polymers also act as a binder to glue the soil particles together and reduce dust and stabilize the entire soil matrix [8].

Extensive researches have been conducted using fly ash (FA) for stabilization of different types of soils including BC soil. Leelavathamma and Pandian [9] studied on fly ash with BC soil in layered system; it was observed that the BC soil and the top FA layer improve the CBR strength due to the pozzolanic reaction of FA. The addition of FA to BC soil results in significant improvement in the CBR, due to the pozzolanic effect and, hence, it can be used as a base material for pavements. The presence of calcium in FA results in the pozzolanic reaction leading to increased strength upon soaking, and in case of FA with low calcium content, the soaked CBR will be less than the unsoaked CBR [10, 11]. Kim et al. [12] studied the effect of lignin-based coproduct and FA on sandy clay. Unconfined compressive strength (UCS) samples were tested on dry and wet conditions and observed that the biofuel coproducts had excellent resistance to moisture degradation for silty clay soil. The sulphonated oil-treated materials had an increase in strength over the test period, and it was observed that the stabilizers need curing time of a few dry months to reach their maximum strength. Santoni et al. [13]; Tingle and Santoni [14] conducted experiments to evaluate the stabilization of clay soils and silty sand with nontraditional stabilizers, including an acid, enzymes, a lignosulfonate, a petroleum emulsion, polymers, and a tree resin. Although many works have been carried out on soil stabilization with FA, the literature indicates minimal studies on the stabilization of $\mathrm{BC}$ soil with the combination of both electrolyte lignin stabilizer (ELS) and FA for different curing days.

\section{Objectives}

The main objective of the current study is to improve the geotechnical properties of BC soil, by stabilizing with a commercially available electrolyte lignin stabilizer and fly ash (Class F) at varying curing periods and to check the laboratory performance and the long-term durability of these stabilized soils.

\section{Materials Used}

\section{Materials}

This study was carried out on BC soil which was procured from a site in North Karnataka, India, where the soil is abundantly available. ELS is a new advanced lignosulphonate liquid ionic organic compound suitable for soil stabilization. This chemical is available in the liquid form and is to be diluted in water at specified proportion before mixing with the soil. BC soil has low strength in terms of CBR and undergoes volume change with seasonal variation in moisture content, resulting in swelling and shrinkage. Hence, BC soil alone cannot be used in pavement construction. The ELS has a catalyst effect when combined in clay soil with 5-10 \% FA by weight of soil. A constant $6 \%$ FA was used for further improvement of soil, which acts as a cementitious stabilizer for soil improvement and is highly recommended to use in combination with ELS for a higher strength subgrade. FA is a waste material and is 
easily available; hence, its use has an additional advantage of environmental friendliness by means of reducing its disposal in landfills. FA used in the study was provided by Thermal Power Station, Raichur, Karnataka, India. Physical properties of ELS and FA are tabulated in Tables 1 and 2.

\section{Chemical Dosage}

Dosage rates can be specified in different manners, but the most common way is based on the dry weight of soil to be treated. Dosage of $1 \mathrm{ml}$ of concentrated ELS liquid for $3 \mathrm{~kg}$ of soil was considered as per the manufacture's suggestions. Since black cotton soil is a highly clayey soil, higher quantity is required to break down the lattice and maximize the penetration of ELS solution in soil. The amount of stabilizer to be used was calculated from the following method.

MDD of soil : $1.77 \mathrm{~g} / \mathrm{cc}$, OMC of soil : $16.31 \%$, natural moisture content of soil : $6 \%$

Water to be added : $[(16.31-6)+2] \times(3 / 100)=0.369$ litres of water

( $2 \%$ extra water was added to compensate evaporation loss).

One millilitre of chemical is diluted in $369 \mathrm{ml}$ of water and then used with $3 \mathrm{~kg}$ dry soil.

\section{Sample Preparation}

The sample preparation was carried out according to the standard procedure. CBR tests were carried out under both moist and soaked conditions. Optimum moisture content (OMC), obtained from the modified proctor test, was about $16 \%$ for BC soil. To prepare stabilized mixtures, required quantity of FA was added and thoroughly mixed with dry soil and then liquid stabilizer, diluted in water, was added in two stages to prepare more homogenous specimens. In the first stage, half of the water was added to the mixture, followed by 15 min continuous hand mixing, and then the remaining water was added, followed by $5 \mathrm{~min}$ hand mixing. Samples were cured for varying curing periods by maintaining the moisture content. After completion of curing period, specimens for soaked CBR test were placed in water for 4 days and then taken out and allowed to drain before being loaded. For every test conducted, minimum three

Table 1 Properties of ELS

\begin{tabular}{ll}
\hline Description & Properties \\
\hline Form & Liquid \\
Odour & Sharp, sulphurous \\
Colour & Dark amber \\
Wetting ability & Excellent \\
Boiling point & $182^{\circ} \mathrm{C}$ \\
Solubility in water & Complete \\
Specific gravity & 1.7 \\
pH & 1 \\
Weight per gallon & $14.19 \mathrm{lb}$ \\
\hline
\end{tabular}


Table 2 Properties of fly ash

\begin{tabular}{lc}
\hline Properties & Test values \\
\hline Type & Class F \\
Specific gravity & 1.975 \\
Water content (\%) & 0.16 \\
Loss on ignition (\%) & 0.43 \\
Size & $<45 \mu$ \\
pH & 8.12 \\
\hline
\end{tabular}

specimens each were used and the average value was reported, ensuring the precision suggested by the standards.

\section{Methods and Discussion}

The basic tests for grain size distribution (ASTM D 2487), specific gravity (ASTM D 854), Atterberg's limits (ASTM D 4318), compaction characteristics (ASTM D 698), UCS (ASTM D 2166), CBR (ASTM D 1883), permeability (ASTM D 2434), durability (ASTM D 559, 560), etc. were performed. BC soil was stabilized with ELS and FA separately and also with the combinations of ELS and FA. Geotechnical properties of BC soil are summarized in Table 3. UCS test was conducted at OMC and also on the dry and wet sides of OMC to evaluate the loss in strength for the stabilized specimens, due to moisture variations.

\section{Engineering Properties}

The treated and untreated soil samples were tested for consistency limits and modified compaction. Each test was performed within 30 min after mixing. From the test results tabulated in Table 4, it can be seen that engineering properties are slightly enhanced by stabilizing ELS and fly ash alone, whereas better improvement has occurred when these stabilizers were used in combination. The PI values were decreasing as the curing days increased, due to the densification of soil. The addition of ELS and $6 \%$ FA was found to be slightly increasing maximum dry density (MDD) of the treated soil. During compaction, the finer portion of FA may be squeezed into the voids of soil particles, thus resulting in an increase in MDD [15]. Marginal decrease was observed in OMC, which can be attributed to the progressive hydration process of the FA that consumed some amount of water inside the voids.

According to Indian Standards (IS) 2720, Part-XI, FSI was calculated. It can be observed from Table 4 that the FSI values were reduced with the increase in curing days. In this test, soil passing through 425 micron IS sieve was taken, which mainly contains clay particles. In ELS and FA stabilized samples, swelling was significantly reduced due to ELS attack on this clay lattice of the soil, which alters the ionic charge in clay and creates a chemical bond between the clay particles. It reduces shrink and swell by forming a chemical and physical bond between the clay particles that allows the moisture content of the soil to stabilize and reduces the movement of the soil. 
Table 3 Geotechnical properties of natural $\mathrm{BC}$ soil

\begin{tabular}{lll}
\hline S1 no. & Property & BC soil \\
\hline 1 & Specific gravity & 2.5 \\
2 & Grain size distribution (\%) & \\
& (a) Gravel & 04 \\
& (b) Sand & 24 \\
& (c) Silt & 51 \\
& (d) Clay & 21 \\
& Consistency limits (\%) & \\
& Liquid limit & 64 \\
& Plastic limit & 31 \\
5 & Plasticity index & 33 \\
& IS soil classification & CH \\
& Standard compaction & \\
& (a) MDD, $\gamma$ dmax (g/cc) & 1.62 \\
& (b) OMC (\%) & 20.45
\end{tabular}

Modified compaction
(a) MDD, $\gamma d \max (\mathrm{g} / \mathrm{cc})$
(b) OMC (\%)

6

CBR value (\%)

Standard compaction
(a) Unsoaked condition
19.45
(b) Soaked condition
0.98

Modified compaction
(a) Unsoaked condition
(b) Soaked condition
1.04

UCS value $(\mathrm{kPa})$

(a) Standard compaction

(b) Modified compaction

\section{Chemical Analysis}

The chemical compositions of soil, FA and different treated soil combinations were determined and are shown in Table 5. The BC soil used in the present study is mainly composed of silica (57\%) and alumina (8\%). Iron oxide, magnesium oxide and calcium oxide also are present (1-6\%). It was found that adding ELS and FA has high levels of calcium and silica, which leads to its pozzolanic property.

\section{Unconfined Compressive Strength}

UCS test was conducted on untreated and treated soil samples for different curing periods, at $\mathrm{OMC}$ and on the wet and dry sides of $\mathrm{OMC}$ (at $\mathrm{OMC} \pm 2 \%$ ), and the values are presented in Table 6 . As seen from the results, wet and dry side of UCS values has no significant improvement on strength. From Fig. 1, it can be observed that UCS increased for stabilized soil samples and showed an increasing trend with curing period. 
Table 4 Geotechnical properties of stabilized soil

\begin{tabular}{|c|c|c|c|c|c|c|c|c|c|c|}
\hline \multirow{2}{*}{$\begin{array}{l}\text { Mix } \\
\text { Curing days }\end{array}$} & \multirow[t]{2}{*}{ BC soil } & \multicolumn{3}{|c|}{$\mathrm{BC}+\mathrm{ELS}$} & \multicolumn{3}{|c|}{$\mathrm{BC}+\mathrm{FA}$} & \multicolumn{3}{|c|}{$\mathrm{BC}+\mathrm{ELS}+\mathrm{FA}$} \\
\hline & & 1 & 7 & 28 & 1 & 7 & 28 & 1 & 7 & 28 \\
\hline \multicolumn{11}{|c|}{ Consistency limits (\%) } \\
\hline LL & 64 & 60 & 58 & 57 & 58 & 55 & 53 & 55 & 51 & 50 \\
\hline PL & 31 & 33 & 34 & 35 & 31 & 33 & 34 & 29 & 31 & 33 \\
\hline PI & 33 & 27 & 24 & 22 & 27 & 22 & 19 & 26 & 20 & 17 \\
\hline \multicolumn{11}{|c|}{ Modified proctor compaction } \\
\hline $\operatorname{MDD}(\mathrm{g} / \mathrm{cc})$ & 1.77 & 1.77 & 1.79 & 1.85 & 1.77 & 1.80 & 1.85 & 1.77 & 1.80 & 1.88 \\
\hline $\mathrm{OMC}(\%)$ & 16.31 & 16.31 & 16.29 & 16.25 & 16.33 & 16.31 & 16.26 & 16.31 & 16.21 & 16.11 \\
\hline \multicolumn{11}{|c|}{ Free swell index (\%) } \\
\hline FSI & 50 & 19 & 8 & 8 & 11 & 9 & 6 & 9 & 5 & 2 \\
\hline
\end{tabular}

This tendency may be due to the effective cation exchange process in ELS samples which generally takes longer period. Increase in strength of these samples is due to the chemical reaction of ELS with clay lattice of the soil, which alters the ionic charge in clay and creates a chemical bond between the clay particles.

\section{California Bearing Ratio}

CBR test was conducted on untreated and treated soil specimens in soaked and unsoaked conditions for different curing periods at $\mathrm{OMC}$ and $\mathrm{OMC} \pm 2 \%$. From the test results (Table 7), it can be observed that soaked CBR was increased for stabilized soil samples and showed an increasing trend with curing period and also the dry side of OMC provided better strength than the wet side. For unsoaked condition, the variation in CBR can be attributed to the change in particle size distribution as well as the slight pozzolanic effect of the mix. In soaked condition, the low $\mathrm{CBR}$ of $\mathrm{BC}$ soil alone is due to the dominance of the clay fraction. The

Table 5 Chemical composition of BC soil, FA and treated soils

\begin{tabular}{llllll}
\hline Oxides (\%) & BC & FA & BC+ELS & BC+FA & BC+ELS+FA \\
\hline $\mathrm{SiO}_{2}$ & 57.12 & 41.10 & 58.29 & 58.76 & 59.89 \\
$\mathrm{Fe}_{2} \mathrm{O}_{3}$ & 6.08 & 4.50 & 2.71 & 2.01 & 2.18 \\
$\mathrm{Al}_{2} \mathrm{O}_{3}$ & 8.05 & 36.51 & 9.75 & 7.96 & 9.04 \\
$\mathrm{Chloride}$ & 0.085 & 0.10 & 0.11 & 0.13 & 0.12 \\
$\mathrm{Sulphate}$ & 0.091 & 0.042 & 0.025 & 0.032 & 0.052 \\
$\mathrm{CaO}$ & 0.50 & 14.50 & 9.89 & 12.89 & 16.76 \\
$\mathrm{MgO}$ & 0.40 & 4.80 & 0.87 & 1.062 & 1.215 \\
$\mathrm{pH}$ & 8.22 & 8.12 & 8.50 & 8.21 & 8.43 \\
$\mathrm{LOI}$ & 14.67 & 3.30 & - & - & - \\
\hline
\end{tabular}


Table 6 UCS values for untreated and treated samples

\begin{tabular}{|c|c|c|c|c|c|c|c|c|c|c|c|c|}
\hline \multirow{2}{*}{$\begin{array}{l}\text { Mix } \\
\text { Curing days }\end{array}$} & \multicolumn{3}{|c|}{ BC soil } & \multicolumn{3}{|c|}{$\mathrm{BC}+\mathrm{ELS}$} & \multicolumn{3}{|c|}{$\mathrm{BC}+\mathrm{FA}$} & \multicolumn{3}{|c|}{$\mathrm{BC}+\mathrm{ELS}+\mathrm{FA}$} \\
\hline & 1 & 7 & 28 & 1 & 7 & 28 & 1 & 7 & 28 & 1 & 7 & 28 \\
\hline \multicolumn{13}{|l|}{ UCS $(\mathrm{kPa})$} \\
\hline OMC & 173 & 207 & 231 & 415 & 792 & 971 & 324 & 513 & 684 & 544 & 890 & 1204 \\
\hline $\begin{array}{l}\text { OMC } \\
-2 \%\end{array}$ & 98 & 122 & 173 & 313 & 578 & 758 & 291 & 473 & 615 & 452 & 805 & 1063 \\
\hline $\begin{array}{l}\mathrm{OMC} \\
+2 \%\end{array}$ & 138 & 166 & 192 & 289 & 634 & 838 & 264 & 426 & 593 & 410 & 746 & 946 \\
\hline
\end{tabular}

higher CBR of ELS and FA are due to its better strength characteristics, primarily because of friction. The increase in soaked CBR with the addition of ELS and FA to $\mathrm{BC}$ soil is mainly because of two factors: mobilization of frictional resistance and other pozzolanic reaction in the presence of water due to the free lime content in FA [16]. Figure 2 depicts the variation of soaked CBR values for different combinations at OMC with curing periods. The soaked CBR of ELS and FA samples increased rapidly during the 28 days curing, which is due to the cementation caused by the pozzolanic reaction between the soil particles. For ELS and FA mix, the soaked CBR value increased to 12 , which is rated as fair subgrade [17].

\section{Durability Test}

Durability is defined as the ability of a material to retain stability and integrity over years of exposure to the destructive forces of weathering and is one of the most important elements for stabilized soil. An effective soil stabilizer not only provides initial strength gain, but the strength gained should not get reduced according to seasonal changes. Hence, checking the durability is vital before recommending the stabilizer for practical applications. There are mainly two tests for durability, the wet-dry (WD) and freeze-thaw (FT) test. For the present study, the durability of chemically stabilized soil was assessed as per ASTM D 559 and

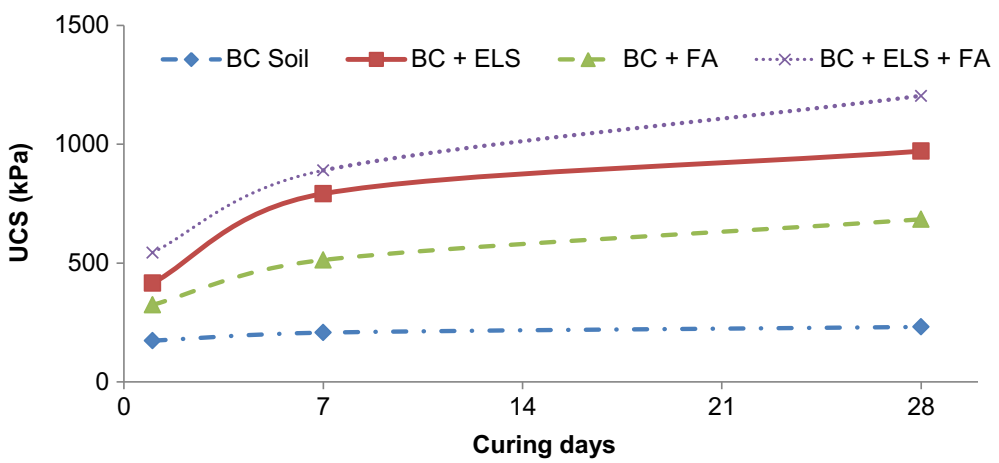

Fig. 1 Variation of UCS values at OMC 
Table 7 CBR values (\%) for untreated and treated samples

\begin{tabular}{|c|c|c|c|c|c|c|}
\hline \multirow[t]{2}{*}{ Curing days } & \multicolumn{2}{|c|}{ OMC $-2 \%$} & \multicolumn{2}{|l|}{$\mathrm{OMC}$} & \multicolumn{2}{|c|}{$\mathrm{OMC}+2 \%$} \\
\hline & Unsoaked & Soaked & Unsoaked & Soaked & Unsoaked & Soaked \\
\hline \multicolumn{7}{|l|}{$\mathrm{BC}$ soil } \\
\hline 1 & 25 & 1 & 26 & 1 & 17 & $<1$ \\
\hline 7 & 24 & 2 & 28 & 1 & 19 & $<1$ \\
\hline 28 & 29 & 1 & 31 & 1 & 21 & $<1$ \\
\hline \multicolumn{7}{|l|}{$\mathrm{BC}+\mathrm{ELS}$} \\
\hline 1 & 18 & 2 & 33 & 2 & 15 & $<1$ \\
\hline 7 & 23 & 3 & 40 & 4 & 14 & 1 \\
\hline 28 & 26 & 4 & 49 & 5 & 11 & 1 \\
\hline \multicolumn{7}{|l|}{$\mathrm{BC}+\mathrm{FA}$} \\
\hline 1 & 22 & 2 & 31 & 3 & 29 & $<1$ \\
\hline 7 & 32 & 4 & 38 & 5 & 31 & 2 \\
\hline 28 & 39 & 6 & 42 & 6 & 33 & 3 \\
\hline \multicolumn{7}{|c|}{$\mathrm{BC}+\mathrm{ELS}+\mathrm{FA}$} \\
\hline 1 & 21 & 4 & 47 & 6 & 33 & 3 \\
\hline 7 & 30 & 6 & 49 & 10 & 37 & 5 \\
\hline 28 & 43 & 7 & 54 & 12 & 43 & 6 \\
\hline
\end{tabular}

560. For both tests, 7 days moist cured UCS soil specimens were selected; initially, specimen weight and height was measured. In WD cycles, the sample was immersed in water for $5 \mathrm{~h}$ and then the same sample was kept in oven at $71{ }^{\circ} \mathrm{C}$ for $42 \mathrm{~h}$. In FT cycles, the sample was kept in freezer at $-10{ }^{\circ} \mathrm{C}$ for $22 \mathrm{~h}$ and then it was subjected to thawing for $22 \mathrm{~h}$ at room temperature. Brushing was done after each cycle, and the weight loss after each wetting and drying cycle was calculated separately. Figure 3a,b shows the soil samples during durability cycle

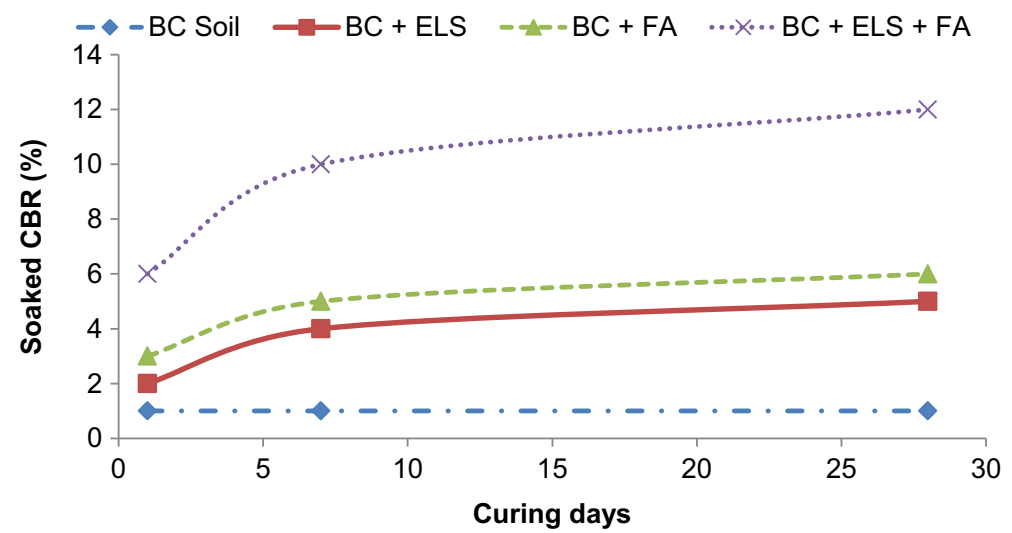

Fig. 2 Variation of soaked CBR values at OMC 


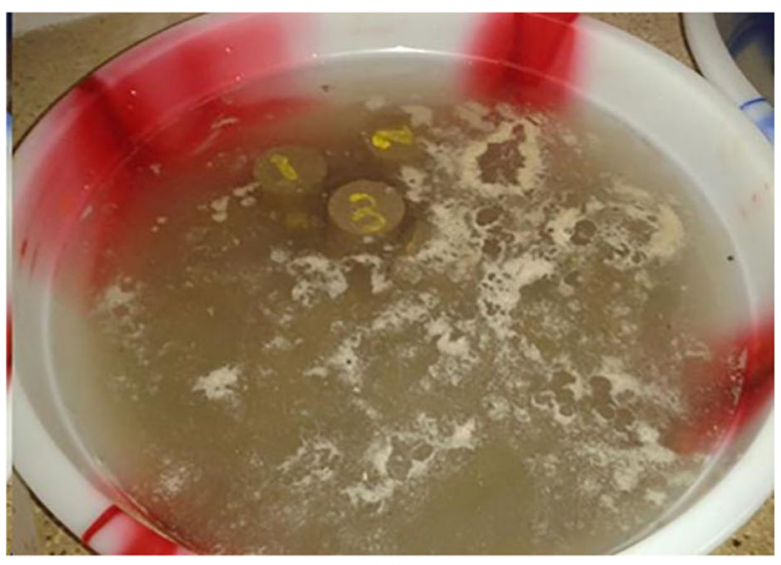

(a)

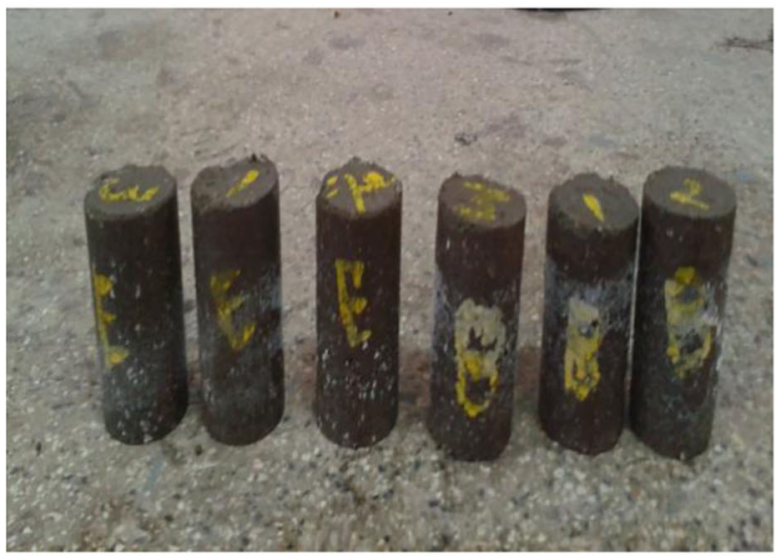

(b)

Fig. 3 Specimens during durability test: a wetting cycle; b thawing cycle

test. Both the stabilized samples could not withstand for more than five WD cycles, whereas in FT test, all the samples could withstand 12 cycles and percentage of loss was within the specified maximum of $14 \%$ are tabulated in Table 8. During FT cycles, the water volume in the soil pores increases due to freezing leading to expansion and formation of fractured pores on the specimen. When it is subjected for thawing, water flows through these pores and the deterioration gets intensified. The effects of FT cycles on the deterioration degree vary depending on the soil properties [18].

\section{Coefficient of Permeability}

The coefficient of permeability test was conducted using falling head method for untreated and treated soil mixes. The soil samples were prepared at OMC and MDD conditions. The treated samples were tested at 7 days curing period. The 
Table 8 Freeze and thaw values for treated and untreated samples

\begin{tabular}{|c|c|c|c|c|c|c|c|}
\hline \multicolumn{2}{|c|}{ No. of cycles } & \multicolumn{2}{|l|}{ BC soil } & \multicolumn{2}{|c|}{ BC soil+ELS } & \multicolumn{2}{|c|}{ BC soil+ELS+FA } \\
\hline & & Weight (g) & Weight loss (\%) & Weight (g) & Weight loss $(\%)$ & Weight (g) & Weight loss $(\%)$ \\
\hline \multirow[t]{2}{*}{1} & Freeze & 160.7 & 0.31 & 160.0 & 0.06 & 157.1 & 0.19 \\
\hline & Thaw & 152.1 & 5.65 & 156.8 & 2.06 & 151.0 & 4.07 \\
\hline \multirow[t]{2}{*}{2} & Freeze & 153.3 & 4.90 & 157.2 & 1.81 & 153.0 & 2.80 \\
\hline & Thaw & 150.0 & 6.95 & 156.7 & 2.12 & 152.0 & 3.43 \\
\hline \multirow[t]{2}{*}{3} & Freeze & 151.7 & 5.89 & 157.2 & 1.81 & 153.7 & 2.35 \\
\hline & Thaw & 148.7 & 7.75 & 154.6 & 3.44 & 151.4 & 3.81 \\
\hline \multirow[t]{2}{*}{4} & Freeze & 149.7 & 7.13 & 155.8 & 2.69 & 151.7 & 3.62 \\
\hline & Thaw & 148.0 & 8.19 & 154.3 & 3.62 & 151.3 & 3.88 \\
\hline \multirow[t]{2}{*}{5} & Freeze & 149.1 & 7.51 & 155.3 & 3.00 & 151.8 & 3.56 \\
\hline & Thaw & 148.1 & 8.13 & 154.0 & 3.81 & 151.2 & 3.94 \\
\hline \multirow[t]{2}{*}{6} & Freeze & 148.6 & 7.82 & 155.4 & 2.94 & 151.5 & 3.75 \\
\hline & Thaw & 148.3 & 8.00 & 154.2 & 3.69 & 151.7 & 3.62 \\
\hline \multirow[t]{2}{*}{7} & Freeze & 149.3 & 7.38 & 156.7 & 2.12 & 151.7 & 3.62 \\
\hline & Thaw & 147.3 & 8.62 & 153.8 & 3.94 & 151.5 & 3.75 \\
\hline \multirow[t]{2}{*}{8} & Freeze & 148.3 & 8.00 & 154.5 & 3.50 & 151.3 & 3.88 \\
\hline & Thaw & 148.4 & 7.94 & 153.5 & 4.12 & 151.1 & 4.00 \\
\hline \multirow[t]{2}{*}{9} & Freeze & 149.3 & 7.38 & 155.1 & 3.12 & 151.2 & 3.94 \\
\hline & Thaw & 147.0 & 8.81 & 152.5 & 4.75 & 151.0 & 4.07 \\
\hline \multirow[t]{2}{*}{10} & Freeze & 148.3 & 8.00 & 151.2 & 5.56 & 151.5 & 3.75 \\
\hline & Thaw & 146.7 & 9.00 & 152.2 & 4.93 & 151.1 & 4.00 \\
\hline \multirow[t]{2}{*}{11} & Freeze & 145.6 & 9.68 & 151.9 & 5.12 & 151.3 & 3.88 \\
\hline & Thaw & 146.3 & 9.24 & 151.9 & 5.12 & 151.1 & 4.00 \\
\hline \multirow[t]{2}{*}{12} & Freeze & 147.4 & 8.56 & 152.7 & 4.62 & 150.0 & 4.70 \\
\hline & Thaw & 147.0 & 8.81 & 152.5 & 4.75 & 151.0 & 4.07 \\
\hline
\end{tabular}

treated soil samples were less permeable in nature, and the values are depicted in Fig. 4. Combination of ELS and FA shows a significant reduction in permeability values than the other mixes. It might be the ELS liquid works on breaking down

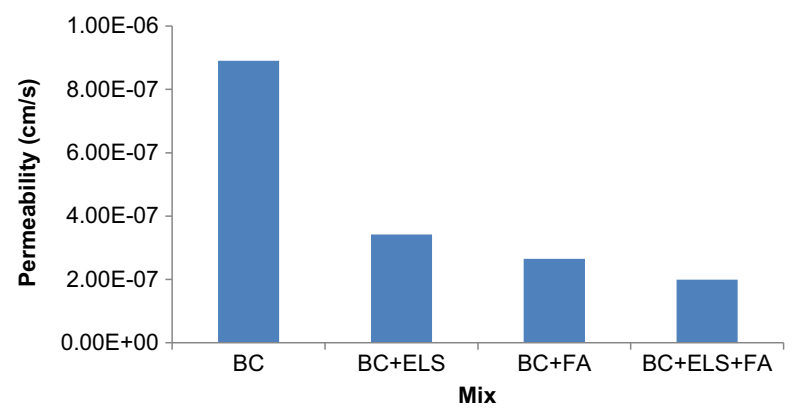

Fig. 4 Coefficient of permeability values 
the capillary action of soil particles and thus it reduced the moisture retentive nature of $\mathrm{BC}$ soil.

\section{Fatigue Test}

Fatigue life is the number of load cycles corresponding to the failure of the specimen under repeated loading or number of loading. To investigate the fatigue behaviour of stabilized soil, specimens were exposed to repeated loading in the laboratory. The number of loading cycles varied depending on curing period, and other parameters such as stress, frequency of loading and type of wave form. Fatigue load test setup is shown in Fig. 5a. The equipment is capable of applying the repeated loads at a frequency of 1 to $10 \mathrm{~Hz}$ with rest period of 0.1 to $0.9 \mathrm{~s}$. The following testing procedure is adopted.

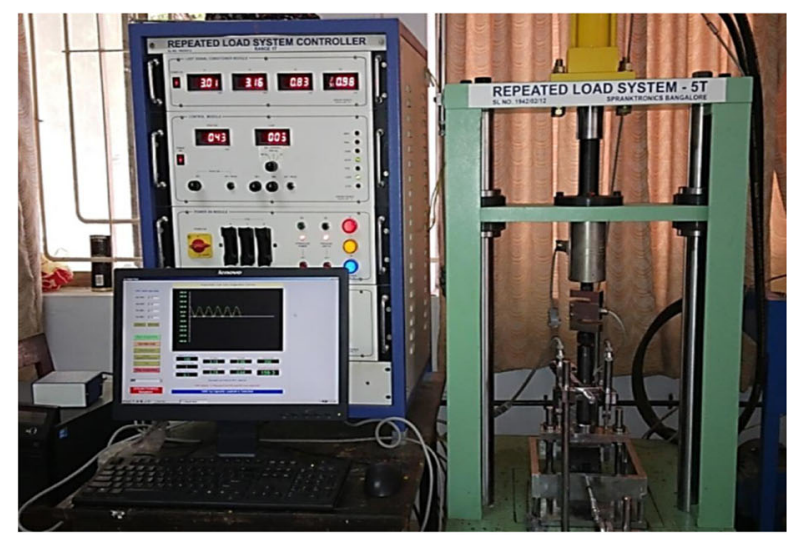

(a)

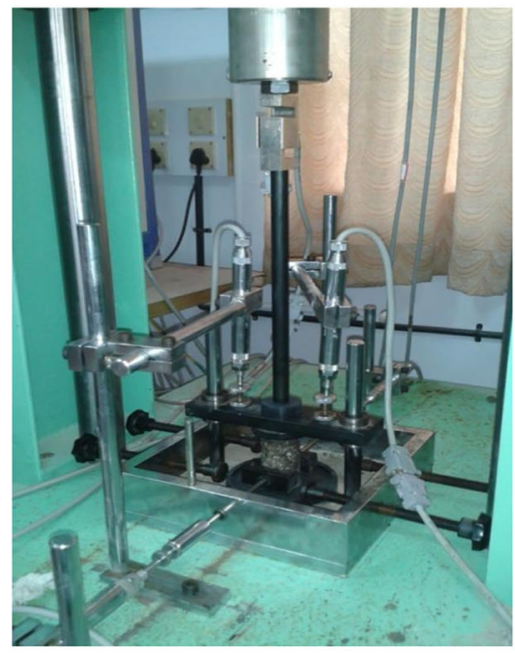

(b)

Fig. 5 a Fatigue load test setup; b specimen arrangement 
Table 9 Fatigue test results of untreated and treated $\mathrm{BC}$ soil

\begin{tabular}{lll}
\hline $\begin{array}{l}\text { UCS } \\
(\mathrm{kg})\end{array}$ & $\begin{array}{l}\text { Applied load } \\
(\mathrm{kg})\end{array}$ & $\begin{array}{l}\text { Fatigue life } \\
\text { (no. of cycles) }\end{array}$ \\
\hline $\begin{array}{l}\text { BC soil } \\
24\end{array}$ & 8 & 10,552 \\
& 12 & 7227 \\
& 16 & 5475 \\
BC+ELS & & \\
92 & 30 & 67,795 \\
& 46 & 46,284 \\
& 61 & 33,208 \\
BC+FA & & \\
60 & 20 & 91,990 \\
& 30 & 61,801 \\
& 40 & 45,988 \\
BC+ELS+FA & & 138,119 \\
103 & 34 & 96,715 \\
& 52 & 71,318 \\
\hline
\end{tabular}

- The cylindrical specimen is mounted on the loading frame and the deflection sensing transducers (LVDT) are set to read the deformation of the specimen. The load cell is brought in contact with the specimen surface (Fig. 5b).

- In the control unit, through the dedicated software, the selected loading stress level, frequency of loading and the type of wave form are fed in to the loading device.

- The loading system and the data acquisition system are switched on simultaneously, and the process of fatigue load application on the test specimen is initiated.

- The repeated loading, at the designated excitation level (i.e. at the selected stress level and frequency) is continued till the failure of the test specimen.

- The failure pattern of the test specimen is noted down manually.

Repeated loading test was conducted on untreated and treated soil samples cured for 7 days, and the results are shown in Table 9. The UCS samples are tested at frequency of $1 \mathrm{~Hz}$ and rest period of $0.1 \mathrm{~s}$. Load considered was $1 / 3 \mathrm{rd}, 1 / 2$ and $2 /$ 3 rd fractions of UCS values. All the soil samples were subjected to moist curing. From Table 9, it is evident that the stabilized soil samples have more fatigue life than the conventional ones.

\section{Conclusions}

In this study, BC soil was stabilized with ELS, FA and a combination of these materials, and their performance was evaluated using a series of laboratory experiments. The important conclusions obtained from the results are summarized as follows: 
- Basic geotechnical properties like Atterberg limits, compaction characteristics and permeability got improved when the soil was treated with ELS and FA.

- Curing period also played a significant role in stabilization.

- The UCS enhancement after 28 days curing, for BC+ELS, BC+FA and BC+ ELS+FA was 4.2, 3.0 and 5.2 times that of the natural BC soil, respectively.

- All stabilized soil mixes showed a significant increase in the soaked CBR values, with an improvement of 2 to 12 times that of normal soil.

- The ELS and FA stabilization controlled the critical swelling problem of BC soil, by significantly reducing the free swell index from 50 to $2 \%$.

- Treatment of ELS and FA provided 6 to 13 times higher fatigue life to the BC soil.

Considering these findings, it can be concluded that ELS and FA combination can be used to stabilize BC soils. ELS and fly ash alone may not provide comprehensive stabilization, and hence, it is recommended to use both the stabilizers in combination in $\mathrm{BC}$ soil stabilization. The guidelines by Indian Roads Congress suggest pavement sections for different traffic volumes and subgrade conditions starting from $2 \%$ soaked CBR. It also recommends using soil with CBR $>10 \%$ as modified subgrade layer in some cases. In this study, the stabilized soil successfully achieved the soaked CBR criteria and other tests confirmed its suitability as a pavement material.

Acknowledgments The authors sincerely acknowledge Mr. Samir Das Gupta, Proprietor, Terra Nova Technologies, India, for providing material and technical suggestions.

Compliance with Ethical Standards The authors of this manuscript certify that they comply with the ethical guidelines for authorship and publishing in the Journal of Transportation Infrastructure Geotechnology.

\section{References}

1. Lekha, B.M., Shankar, A.U.R., Goutham, S.: Fatigue and engineering properties of chemically stabilized soil for pavements. Indian Geotech. J. 43(1), 96-104 (2013)

2. Nicholls, R.L., Davidson, D.T.: Polyacids and lignin used with large organic cations for soil stabilization. Highw. Res. Board 37, 517-537 (1958)

3. Sinha, S.P., Davidson, D.T., Hoover, J.M.: Lignins as stabilizing agents for northeastern Iowa loess. Iowa Acad. Sci. Proc. 64, 314-347 (1957)

4. Gow, A.J., Davidson, D.T., Sheeler, J.B.: Relative effects of chlorides, lignosulfonates and molasses on properties of a soil-aggregate mix. Highw. Res. Board 282, 66-83 (1961)

5. Davidson, D.T., Handy, R.L.: Soil stabilization. Highway engineering handbook. McGraw-Hill, New York (1960). Sect. 21

6. Puppala, A.J., Hanchanloet, S.: Evaluation of a new chemical (SA-44/LS-40) treatment method on strength and resilient properties of a cohesive soil, pp. 1-11. Proceedings of the Transportation Research Board Annual Meeting, Transportation Research Board, Washington, DC (1999)

7. Tingle, J.S., Santoni, R.L.: Stabilization of clay soils with non-traditional additives, pp. 72-84. Transportation Research Board of the National Academies, Washington, D.C (2003)

8. Brown, J.J., Brandon, T.L., Daniels, W.L., DeFazio, T.L., Filz, G.M., Mitchell, J.K.: Rapid stabilization/ polymerization of wet clay soils: phase I literature review. Air Force Research Laboratory, Tyndall AFB, Florida (2004)

9. Leelavathamma, B., Pandian, N.S.: Effect of class C fly ash on the California bearing ratio behavior of soil-fly ash mixes and layered systems. J. Test. Eval. 33(2), 1-6 (2005)

10. Pandian, N.S., Krishna, K.C.: The pozzolanic effect of fly ash on the California bearing ratio behavior of black cotton soil. J. Test. Eval. 31(6), 479-485 (2003) 
11. Pandian, N.S., Krishna, K.C.: CBR behaviour of fly ash—murrum mixes. Ground Improv. 5(4), 177-181 (2001)

12. Kim, S., Gopalakrishnan, K., Ceylan, H.: Moisture susceptibility of subgrade soils stabilized by ligninbased renewable energy coproduct. J. Transp. Eng. 138, 1283-1290 (2012)

13. Santoni, R.L., Tingle, J.S., Nieves, M.: Accelerated strength improvement of silty sand with nontraditional additives, vol. 3, pp. 4-42. Transportation Research Record 1936, Transportation Research Board, Washington, D.C. (2005)

14. Tingle, J.S., Santoni, R.L.: Stabilization of clay soils with nontraditional additives, pp. 72-84. Transportation Research Record 1819, Transportation Research Board, Washington, D.C. (2003)

15. McManis, K.L., Arman, A.: Class C fly ash as full or partial replacement for portland cement or lime, pp. 68-81. Transportation Research Record 1219, Transportation Research Board, Washington, DC (1989)

16. Sivapullaiah, P.V., Prashanth, J.P., Sridharan, A., Narayana, B.V.: Reactive silica and strength of fly ashes. Geotech. Geol. Eng. 16, 239-250 (1998)

17. Guidelines for the design of flexible pavements for low volume rural roads, IRC:SP:72-2007

18. Hori, M., Morihiro, H.: Micromechanical analysis on deterioration due to freezing and thawing in porous brittle materials. Int. J. Eng. Sci. 36(4), 511-522 (1998) 